\title{
Size-Controllable Synthesis of Hierarchical Copper Carbodiimide Microcrystals and Their Pronounced Photoelectric Response under Visible Light
}

Qihui Liu, ${ }^{a}$ Yufeng Liu, ${ }^{*}{ }^{a}$ Guozhang Dai, ${ }^{b}$ Li Tian,,${ }^{c}$ Jiayue Xu, ${ }^{a}$ Guoying Zhao, ${ }^{a} \mathrm{Na}$ Zhang, ${ }^{a}$ Yongzheng Fang ${ }^{* a}$

${ }^{\mathrm{a}}$ School of Materials Science and Engineering, Shanghai Institute of Technology, Shanghai 200235, P.R. China

${ }^{\mathrm{b}}$ Hunan Key Laboratory for Super-microstructure and Ultrafast Process, School of Physics and Electronics, Central South University, Changsha, Hunan 410083, P.R. China

${ }^{\mathrm{c}}$ College of Electrical and Information Engineering, Hunan Institute of Engineering, Xiangtan 411101, P.R. China

\begin{abstract}
Similar to cupric oxides and sulfides, the nitrogen-containing analogue copper carbodiimide $(\mathrm{CuNCN})$ is considered as a potentially promising photoelectric material. However, there is lack of fundamental investigations on controllable synthesis and photoelectric properties of $\mathrm{CuNCN}$ nano/microcrystals. Herein, a facile method was developed to synthesize high-quality CuNCN semiconductor microcrystals with different sizes and hierarchical nanostructures at room temperature. This reaction was carried out in aqueous solutions, avoiding the involvement of non-aqueous solutions and high temperature solid phase reaction during the synthesis of CuNCN microcrystals. Photoelectric response of as-prepared CuNCN microcrystals was first observed under the irradiation of visible light at room temperature. The aqueous synthetic route can also provide an inspiration to acquire other metal
\end{abstract}


carbodiimides nano/microcrystals.

Keywords: Metal carbodiimides; CuNCN; Microcrystal; Hierarchical nanostructures

\section{Introduction}

Metal carbodiimides/cyanamides are a type of unique compounds, which have attracted great interest of researchers for a few decades. They are potentially functional materials deriving from the two negative charges of carbodiimide/cyanamide anion and the large electron negativity of the terminal nitrogen atoms $[1-6]$. The $[\mathrm{NCN}]^{2-}$ anions in these compounds possesses two forms, namely the symmetrical carbodiimide $[\mathrm{N}=\mathrm{C}=\mathrm{N}]^{2-}$ form and the lower symmetrical cyanamide $[\mathrm{N}-\mathrm{C} \equiv \mathrm{N}]^{2-}$ form [5-8]. Unlike high localized $\mathrm{O} 2 \mathrm{p}^{6}$ states in metal oxides, the electronic states of the $[\mathrm{NCN}]^{2-}$ group are delocalized at valence band maximum and conduction band minimum. The electronic states act as a bridge to form the electron interaction between the central metal cation and the chelated $[\mathrm{NCN}]^{2-}$ anion, which results in nontrivial physical or chemical properties just like the typical semiconductors of pnictides or chalcogenides [9-11]. Therefore, substituting $\mathrm{O}^{2-}$ or $\mathrm{S}^{2-}$ ion in metal oxides or sulfides semiconductor with $[\mathrm{NCN}]^{2-}$ anion may induce new type of semiconductor materials [10-13].

Copper carbodiimide $(\mathrm{CuNCN})$ is a nitrogen-containing analogue of cupric oxide and sulfide [9]. Excellent photoelectric properties are anticipated by substituting $\mathrm{O}^{2-}$ or $\mathrm{S}^{2-}$ ion in copper oxides or sulfides (e.g., $\mathrm{Cu}_{2} \mathrm{O}, \mathrm{CuO}$, and $\mathrm{Cu}_{2} \mathrm{~S}$ ) with $[\mathrm{NCN}]^{2-}$ anion. Moreover, the carrier concentration in $\mathrm{CuNCN}$ is controllable because it is stoichiometic, which is important for photoelectric materials. The crystal structure of $\mathrm{CuNCN}$ is shown in Fig. 1. Each $\mathrm{Cu}$ atom in the $\mathrm{NCN}^{2-}$ unit is coordinated with six $\mathrm{N}$ atoms and forms linear $\mathrm{Cu}-\mathrm{Cu}$ chains with alternative $\mathrm{Cu}-\mathrm{Cu}$ distances of $2.992 \AA$ and $3.432 \AA$. The loosely-packed structure and unique N-C-N species are expected to be 
an excellent photoelectric material. However, there is no study on the photoelectric properties of these metal carbodiimides yet.

In recent years, a large number of metal carbodiimides/cyanamides have been synthesized via different synthetic routes [14-18]. However, the synthetic procedures on metal carbodiimides/cyanamides are generally based on complicated non-aqueous methods with heating or high temperature solid state reaction [16-22]. The synthesis of these compounds via aqueous methods at room temperature was rarely reported $[23,24]$. Moreover, the major attention on these compounds is primarily focused on their crystal structures and electronic properties in these works [25-32]. Therefore, morphology and size-controllable synthesis of nano/micrometer scale metal carbodiimides via aqueous solution method at room temperature is still a challenge. The studies on metal carbodiimides, especially for those of nano/microstructured metal carbodiimides are seldom reported in the past years.

In this paper, a controllable aqueous method was presented to synthesize two types of CuNCN microcrystals (MCs) at room temperature. The size and nanostructure can be tuned via controlling the ratio of $\left[\mathrm{NH}_{3}\right] /\left[\mathrm{Cu}^{+}\right]$. At low ratio of $\left[\mathrm{NH}_{3}\right] /\left[\mathrm{Cu}^{+}\right]$, leaf-like nuclei are assembled to form small MCs with coarse surface. While, irregular monocrystalline $\mathrm{CuNCN}$ nanosheets are formed and assembled into large MCs with smooth surface because the nucleation of CuNCN MCs is seriously suppressed to grow up at high $\left[\mathrm{NH}_{3}\right] /\left[\mathrm{Cu}^{+}\right]$ratio. The photoelectric response of these as-prepared $\mathrm{CuNCN}$ was observed for the first time under the irradiation of visible light at room temperature. The synthetic route can also be applied to acquire other metal carbodiimides MC/NCs with controllable morphology and sizes.

\section{Experimental}

\subsection{Synthesis of CuNCN MCs}

In a typical synthesis of small $\mathrm{CuNCN} \mathrm{MCs}, 0.5 \mathrm{mmol}$ of $\mathrm{CuCl}, 1 \mathrm{~mL}$ of $\mathrm{NH}_{3} \cdot \mathrm{H}_{2} \mathrm{O}\left(\left[\mathrm{Cu}^{+}\right] /\left[\mathrm{NH}_{3}\right]=1: 32\right)$ and $10 \mathrm{~mL}$ of deionized water were in turn added 
into a $20 \mathrm{~mL}$ vial under stirring to form a blue solution. Then $1 \mathrm{mmol}(0.1 \mathrm{M})$ of $\mathrm{H}_{2} \mathrm{NCN}$ solution was added into the vial under stirring for 5 minutes. Finally, a black product was obtained. The products were taken out, and centrifuged to collect at $10000 \mathrm{rmp}$ for 3 minutes.

In a typical synthesis of large $\mathrm{CuNCN} \mathrm{MCs}, 0.5 \mathrm{mmol}$ of $\mathrm{CuCl}, 5 \mathrm{~mL}$ of $\mathrm{NH}_{3} \cdot \mathrm{H}_{2} \mathrm{O}\left(\left[\mathrm{Cu}^{+}\right] /\left[\mathrm{NH}_{3}\right]=1: 160\right)$ and $5 \mathrm{~mL}$ of deionized water were in turn added into a $20 \mathrm{~mL}$ vial under stirring to form a blue solution. Then $1 \mathrm{mmol}(0.1 \mathrm{M})$ of $\mathrm{H}_{2} \mathrm{NCN}$ solution was added into the vial under stirring for 5 minutes. Finally, a black product was obtained. The products were taken out, and centrifuged to collect at $8000 \mathrm{rmp}$ for 3 minutes.

\subsection{Characterization}

Field emission scanning electron microscopy (FESEM) images were acquired using FEI Sirion 200 with an energy dispersive X-ray (EDS) analysis. Low and high resolution transmission electron microscopy (TEM) images and selected area electron diffraction (SAED) were taken on JEOL JEM-2100F at an accelerating voltage of 200 $\mathrm{kV}$. TEM samples were prepared by dip-casting CuNCN MCs dispersed in ethanol onto carbon-coated copper TEM grids. X-ray diffraction (XRD) patterns were collected on a Bruker D8 Focus X-ray diffractometer equipped with a monochromatized source of $\mathrm{CuKa}$ radiation $(\lambda=0.15406 \mathrm{~nm})$ at $1.6 \mathrm{~kW}(40 \mathrm{kV}, 40$ $\mathrm{mA}$ ). The pattern was recorded in a slow-scanning mode with $2 \theta$ from $10^{\circ}$ to $65^{\circ}$ with a scan-rate of $2 \% \mathrm{~min}$. UV-vis-NIR absorbance spectrum was recorded on a Hitachi U-4100 spectrophotometer with a scanning velocity of $240 \mathrm{~nm} / \mathrm{min}$. X-ray photoelectron spectroscopy (XPS) data were obtained using ESCAlab250 X-ray Photoelectron Spectroscopy for surface analysis. Raman spectroscopy was performed on a RenishawinVia Raman microscope using green laser $(\lambda=532 \mathrm{~nm})$ excitation. Fourier transform infrared spectroscopy (FTIR) measurements were carried out in a Shimadzu FTIR Prestige-21. Current-voltage characteristics were measured under a visible light with a $300 \mathrm{~W}$ xenon lamp (filter: $\lambda=420 \mathrm{~nm}$ ). Magnetic properties were 
studied using a Quantum Design physical properties measurement system (PPMS). DC susceptibility was measured under field-cooling (FC) conditions in a $1 * 10^{4}$ Oe magnetic field from 10 to $290 \mathrm{~K}$.

\section{Results and discussion}

Two types of CuNCN products with different sizes and nanostructures were obtained controllably via controlling the ratio of $\left[\mathrm{NH}_{3}\right] /\left[\mathrm{Cu}^{+}\right]$at room temperature. The morphology of two types of CuNCN MCs were characterized by TEM and FESEM images. As shown in Fig. 2(a), S1(a) and S2, monodisperse CuNCN MCs have uniform size with an average diameter of $1.33 \pm 0.15 \mu \mathrm{m}$ at low ratio of $\left[\mathrm{NH}_{3}\right] /\left[\mathrm{Cu}^{+}\right](32: 1)$. Moreover, the MCs have particular secondary nanostructure as shown in FESEM images of an individual CuNCN MC inner (Fig. 2(b) and S1(b)). There were numerous leaf-like CuNCN NCs with an average size of $164 \mathrm{~nm} * 52 \mathrm{~nm}$, which were assembled to form one CuNCN MC. However, large MCs with different nanostructures were obtained via similar synthetic method at high ratio of $\left[\mathrm{NH}_{3}\right] /\left[\mathrm{Cu}^{+}\right]$ (160:1) (Fig. 2(c) and S3(a)). The large MCs were made of a lot of irregular nanoflakes, which form a smooth surface as shown in Fig. 2(d) and S3(b). The average diameter of the CuNCN MCs is $4.12 \pm 0.64 \mu \mathrm{m}$, which is larger than that of MCs assembled by leaf-like nanostructure. Therefore, the ratio of $\left[\mathrm{NH}_{3}\right] /\left[\mathrm{Cu}^{+}\right]$plays an important role in the CuNCN MCs' formation process.

The formation process of the two types of CuNCN MCs with different nanostructures is illustrated in Fig. 3. Firstly, a transparent blue copper ammonia precursor solution was obtained via solving $\mathrm{CuCl}$ into different amounts of ammonia water. An intermediate product, $\mathrm{Cu}_{4}(\mathrm{NCN})_{2} \mathrm{NH}_{3}$, precipitated after $\mathrm{H}_{2} \mathrm{NCN}$ solution was rapidly injected into the precursor at room temperature $[23,24]$. Finally, a deep black precipitation $(\mathrm{CuNCN})$ formed due to the oxidation of $\mathrm{Cu}_{4}(\mathrm{NCN})_{2} \mathrm{NH}_{3}$ in the air.

The morphology of CuNCN products was controlled via changing $\left[\mathrm{NH}_{3}\right] /\left[\mathrm{Cu}^{+}\right]$ratio in the precursor solution. The leaf-like CuNCN 
monocrystalline nuclei were formed rapidly at low $\left[\mathrm{NH}_{3}\right] /\left[\mathrm{Cu}^{+}\right](32: 1)$ ratio. Then the CuNCN nuclei grew and assembled into small spherical CuNCN MCs with an average diameter of $1.33 \pm 0.15 \mu \mathrm{m}$ as shown in Fig. 2(a). However, at high $\left[\mathrm{NH}_{3}\right] /\left[\mathrm{Cu}^{+}\right](160: 1)$ ratio, the $\mathrm{CuNCN}$ nuclei were depressed to grow along a preferable crystal direction, forming irregular flake-like CuNCN nuclei because of the inhibition of more masking agents in the reaction. Finally, the flake-like CuNCN nuclei were assembled into large MCs with a different hierarchical nanostructure.

In the synthetic process, $\mathrm{CuCl}$ was difficult to dissolve completely when the ratio of $\left[\mathrm{NH}_{3}\right] /\left[\mathrm{Cu}^{+}\right]$is lower than $32: 1$. However, the reaction was very slow when the ratio of $\left[\mathrm{NH}_{3}\right] /\left[\mathrm{Cu}^{+}\right]$is higher than $160: 1$ because of the inhibition of more masking agent. In this process, the production of $\mathrm{CuNCN}$ MCs reduced gradually. In addition, CuNCN MCs can be synthesized via substituting $\mathrm{CuCl}$ with $\mathrm{CuCl}_{2}$ as copper precursor. It is obvious that morphology of the product is different when $\mathrm{CuCl}$ was used as the precursor because the different cohesive abilities between $\mathrm{CuCl}$ and $\mathrm{CuCl}_{2}$ with $\mathrm{NH}_{3} \cdot \mathrm{H}_{2} \mathrm{O}$. The CuNCN MCs is irregular, especially for higher ratio of $\left[\mathrm{NH}_{3}\right] /\left[\mathrm{Cu}^{2+}\right](160: 1)$ as shown in Fig. S4. Moreover, a lot of flake-like CuNCN MCs formed in the wall of vial at high $\left[\mathrm{NH}_{3}\right] /\left[\mathrm{Cu}^{2+}\right](160: 1)$ ratio (Fig. S5).

To further investigate the formation process of $\mathrm{CuNCN}$ MCs with different hierarchical nanostructures, TEM images of CuNCN MCs with leaf-like secondary nanostructure were obtained as shown in Fig. 4(a) and 4(b). The diameter of the individual CuNCN MC is $1.23 \mu \mathrm{m}$, which is consisted with the average diameter calculated from FESEM image. One MC consists of a lot of leaf-like NCs, which can be obviously observed in the edge of the MC. However, there is indistinct in the middle of the $\mathrm{MC}$ because of larger thickness of the MC. The SEAD of the leaf-like part in the MC indicates that it is single-crystalline (Fig. 4(d)). The leaf-like single crystal nucleates along (120) crystalline plane as shown in Fig. 4(c). All of the results from TEM images further prove the formation mechanism as mentioned in Fig. 3. 
The crystal structures of two CuNCN MCs were confirmed by XRD patterns. The typical XRD patterns of the two CuNCN MCs can be indexed with the calculated diffraction pattern of CuNCN (ICSD\#161461) as shown in Fig. S6 [22]. Diffraction peaks of large size CuNCN MCs at $2 \theta$ degrees of $18.7^{\mathrm{o}}, 28.6^{\mathrm{o}}, 30.2^{\mathrm{o}}, 33.2^{\mathrm{o}}, 34.5^{\mathrm{o}}, 38.4^{\mathrm{o}}, 48.3^{\mathrm{o}}, 51.4^{\mathrm{o}}, 53.7^{\mathrm{o}}, 57.5^{\mathrm{o}}$ and $62.2^{\mathrm{o}}$ correspond to (110), (120), (-110), (211), (-111), (103), (030), (0-31), (-122), (2-13) and (-2-32) planes of CuNCN MCs respectively (Fig. 5(a)). Diffraction peaks of small CuNCN MCs are similar to those of large MCs except for the disappearance of diffraction peaks at $2 \theta$ degrees of $27.0^{\circ}, 44.6^{\circ}$ and $52.8^{\circ}$ corresponding to $(-111),(103)$ and $(-122)$ planes due to their worse crystallinity comparing to large MCs. In addition, the diffraction peaks of small MCs display a little right shift and wider full width at half maximum compared with that of large CuNCN MCs because of their smaller size of crystalline grains and worse crystallinity.

The UV-vis-NIR absorbance spectroscopy of CuNCN MCs is shown in Fig. 5(b). The result indicates the absorption of CuNCN MCs range from ultraviolet to near-infrared region of $1200 \mathrm{~nm}$. CuNCN MCs present a deep black color as indicated in Fig. 3. It is estimated that the band gap of CuNCN MCs is $\sim 0.92 \mathrm{eV}$ by plotting $(\alpha \mathrm{h} v)^{2}$ (the square of the absorption coefficient $(\alpha)$ multiplied by the photon energy (hv)) versus hv as shown in Fig. 5(b). The band gap locates in the range of optimal band $(0.8-1.8 \mathrm{eV})$ for photovoltaic materials, which expands the family of $\mathrm{Cu}$ compounds (cupric oxides and sulfides) for solar applications. However, copper oxides mainly refer to $\mathrm{Cu}_{2} \mathrm{O}$ and $\mathrm{CuO}$, with the band gaps of 2.0-2.2 $\mathrm{eV}$ and 1.2-1.9 eV, respectively. The carrier concentration of $\mathrm{Cu}_{x} \mathrm{~S}(x=0.5-2)$ are different, depending on their composition. However, $\mathrm{CuNCN}$ is stoichiometric, which makes it with the steady carrier concentration. This is good for its further applications in the photoelectric devices.

Raman spectrum of CuNCN MCs was performed to confirm molecular structure of the materials. The raman peak of CuNCN MCs locates in 1091 
$\mathrm{cm}^{-1}$, which is corresponding to the typical molecular vibration of CuNCN. However, the peak intensity is low and the full width at half maximum is wide due to the worse crystallinity of MCs compared to the bulk materials. In addition, FTIR spectra of MCs shows strong absorption peak located at 2028 $\mathrm{cm}^{-1}$, which ascribes to the asymmetric stretching vibration of NCN group $\left(v_{\mathrm{as}(\mathrm{NCN})}\right)$ (Fig. 5(d)). This value is consistent with the reported result (2010 $\left.\mathrm{cm}^{-1}\right)$ in the references $[11,22]$. NCN deformation vibration $\left(\delta_{(\mathrm{NCN})}: 688 \mathrm{~cm}^{-1}\right.$ and $2 \delta_{(\mathrm{NCN})}: 1176 \mathrm{~cm}^{-1}$ ) are weaker, which was also found in the references as depicted in Fig. 5(d). Magnetic properties were measured under field-cooling condition in a $1 * 10^{4}$ Oe magnetic field from 10 to $290 \mathrm{~K}$. The temperature dependence of the magnetic susceptibility indicates that the material is paramagnetic as shown in Fig. S7, in agreement with the reported results $[33,34]$.

To confirm the compositions and chemical states of elements in CuNCN samples, XPS test was performed as shown in Fig. 6(a, b, c and d), corresponding to XPS survey of all elements, $\mathrm{Cu} 2 \mathrm{p}, \mathrm{C} 1 \mathrm{~s}$, and N1s, respectively. There are two narrow and symmetric peaks at the binding energy of $933.1 \mathrm{eV}$ and $953.2 \mathrm{eV}$ in Fig. 6(b), corresponding to $\mathrm{Cu} 2 \mathrm{p}_{3 / 2}$ and $\mathrm{Cu} 2 \mathrm{p}_{1 / 2}$ with a peak splitting of $20.1 \mathrm{eV}$. There are several satellite peaks at the $943.0 \mathrm{eV}, 944.6 \mathrm{eV}, 956.2 \mathrm{eV}$ and $963.2 \mathrm{eV}$ corresponding to $\mathrm{Cu}$ (II), which indicates the $\mathrm{Cu}$ (I) in the reactant of $\mathrm{CuCl}$ transform to $\mathrm{Cu}$ (II) in the reaction. In addition, the peaks at the $934.5 \mathrm{eV}$ and $937 \mathrm{eV}$ might arise from a little $\mathrm{CuCl}_{2}$ due to the oxidized $\mathrm{Cu}$ (I) in the process of the reaction. There is a pronounced peak of $\mathrm{C} 1 \mathrm{~s}$ at binding energy of $285.0 \mathrm{eV}$ resulting from carbon in the environment (Fig. 6(c)). The other two weaker peak at $285.3 \mathrm{eV}$ and $286.4 \mathrm{eV}$ arising from $\mathrm{C}-\mathrm{O}$ and $\mathrm{C}=\mathrm{N}$ bonds respectively [35-37]. Fig. 6(d) is the XPS of $\mathrm{N} 1 \mathrm{~s}$ located at the bonding energy of $397.9 \mathrm{eV}$ and $400.3 \mathrm{eV}$, corresponding to $\mathrm{N}-\mathrm{O}$ and $\mathrm{N}=\mathrm{C}$ bonds stemming from environment [37-39]. The peak at $398.9 \mathrm{eV}$ belongs to remained $\mathrm{NH}_{3}$ at the surface of CuNCN. All these confirm that the products are composed of $\mathrm{CuNCN}$. 
Photoelectric properties were performed under the irradiation of visible light at room temperature (Fig. 7). The CuNCN MCs with small sizes were pressed into $\sim 1 \mathrm{~mm}$ thick film, on which silver paste was dropped to form a sandwich structure (inset in Fig. 7). Current-voltage (I-V) curve of CuNCN MCs film reveals pronounced photoelectric response comparing to the non-irradiated curve. The photocurrent density increased more than 8 times of dark current density from $1.39 \mu \mathrm{A} / \mathrm{cm}^{2}$ to $11.6 \mu \mathrm{A} / \mathrm{cm}^{2}$ at bias voltage of $1 \mathrm{~V}$, which indicates that $\mathrm{CuNCN}$ MCs own good photoelectric properties originating from intense absorption for visible light region as shown in the UV-vis absorbance spectroscopy of CuNCN MCs (Fig. 5b). In addition, photoelectric properties of CuNCN MCs with large sizes were also measured. The measured results indicate that the photoelectric properties of $\mathrm{CuNCN}$ MCs don't obviously depend on the size of MCs.

\section{Conclusions}

In summary, a controllably synthetic method was presented to fabricate two types of $\mathrm{CuNCN}$ MCs with different sizes and hierarchical nanostructures at room temperature. The stoichiometric CuNCN MCs have a band gap of $\sim 0.92 \mathrm{eV}$, which is similar with the bandgap of copper oxide and sulfide. The result indicates that CuNCN might be potential as a good photoelectric material. The synthetic route can be exploited to acquire size- and morphology-controllable metal carbodiimides NC/MCs.

\section{Acknowledgements}


This work was supported by NSF of China (Grant Nos. 51472162, 51402335), Scientific Research Fund of Hunan Provincial Education Department (Grant No. 14B041). The authors would like to thank Dr. Hao Yin for the help on XPS results and Dr. Ganghua Zhang on crystal structure.

\section{References}

[1] S. Ning, J.A. Madeleine, A cooper-carbodiimide approach to the phomopsin tripeptide side chain, Tetrahedron. Lett. 50 (2009) 6748-6750.

[2] A.L. Tchougreeff, R. Dronskowski, d-d spectra of transition-metal carbodiimides and hydrocyanamides as derived from many-particle effective hamiltonian calculations, J. Phys. Chem. A. 115 (2011) 4547-4552.

[3] F. Duvernay, T. Chiavassa, F. Borget, J.-P. Aycard, Carbodiimide production from cyanamide by UV irradiation and thermal reaction on amorphous water ice, J. Phys. Chem. A. 109 (2005) 603-608.

[4] M. Becker, M. Jansen, Synthesis and characterisation of mercury cyanamide, Z. Anorg. Allg. Chem. 626 (2000) 1639-1641.

[5] L. Stork, X. Liu, B.P.T. Fokwa, R. Dronskowski, crystal structure determination of thallium carbodiimide, $\mathrm{Tl}_{2} \mathrm{NCN}, \mathrm{Z}$. Anorg. Allg. Chem. 633 (2007) 1339-1342.

[6] F. Duvernay, T. Chiavassa, F. Borget, J.P. Aycard, experimental study of water-Ice catalyzed thermal isomerization of cyanamide into carbodiimide: implication for prebiotic chemistry, J. Am. Chem. Soc. 126 (2004) $7772-7773$.

[7] F. Tordini, A. Bencini, M. Bruschi, L.D. Gioia, G. Zampella, P. Fantucci, Theoretical study of hydration of cyanamide and carbodiimide, J. Phys. Chem. A. 107 (2003) 1188-1196.

[8] A. Zorko, P. Jeglic, A. Potocnik, D. Arcon, A. Balcytis, Z. Jaglicic, X. Liu, A.L. Tchougreeff, R. Dronskowski, Unconventional magnetism in a 
nitrogen-containing analog of cupric oxide, Phys. Rev. Lett. 107 (2011) $(1-4)$.

[9] H. Liu, W. Klein, H. Bender, M. Jansen, High pressure behavior of mercury cyanamide $\mathrm{HgCN}_{2}$, Z. Anorg. Allg. Chem. 628 (2002) 4-6.

[10] W. Zhao, Y. Liu, J. Liu, I.W. Chen, F. Huang, J. Lin, Controllable synthesis of silver cyanamide as a new semiconductor photocatalyst under visible-light irradiation, J. Mater. Chem. A. 1 (2013) 7942-7948.

[11] X. Liu, R. Dronskowski, R. Glaum, A.L. Tchougreeff, Experimental and quantum-chemical investigation of the UV/Vis absorption spectrum of manganese carbodiimide, MnNCN, Z. Anorg. Allg. Chem. 636 (2010) 343-348.

[12] X. Liu, L. Stork, M. Speldrich, H. Lueken, R. Dronskowski, FeNCN and $\mathrm{Fe}(\mathrm{NCNH})_{2}$ : synthesis, structure, and magnetic properties of a nitrogen-based pseudo-oxide and -hydroxide of divalent iron, Chem. Eur. J. 15 (2009) 1558-1561.

[13] W. Liao, C. Hu, R.K. Kremer, R. Dronskowski, Rare-earth-metal tetrahedra and condensed alkali-metal iodide octahedra in two novel lithium europium carbodiimide iodides, $\mathrm{LiEu}_{2}(\mathrm{NCN}) \mathrm{I}_{3}$ and $\mathrm{LiEu}_{4}(\mathrm{NCN})_{3} \mathrm{I}_{3}$, Inorg. Chem. 43 (2004) 5884-5890.

[14] P. Kroll, M. Andrade, X. Yan, E. Ionescu, G. Miehe, R. Riedel, Isotropic negative thermal expansion in $\beta-\operatorname{Si}(\mathrm{NCN})_{2}$ and its origin, J. Phy. Chem. C. $116(2012) 526-531$.

[15] C. Wickleder, Thiocyanates as novel host lattices for emitting rare earth ions: luminescence of $\mathrm{Si}(\mathrm{NCN})_{2}: \mathrm{Eu}^{2+}$, Chem. Mater. 17 (2005) 1228-1233.

[16] M. Krott, X. Liu, B.P.T. Fokwa, M. Speldrich, H. Lueken, R. Dronskowski, Synthesis, crystal-structure determination and magnetic properties of two new transition-metal carbodiimides: CoNCN and NiNCN, Inorg. Chem. 46 (2007) 2204-2207.

[17] M. Becker, J. Nuss, M. Jansen, Synthesis and characterization of sodium cyanamide, Z. Anorg. Allg. Chem. 626 (2000) 2505-2508. 
[18] M. Krings, G. Montana, R. Dronskowski, C. Wickleder, $\alpha-\mathrm{SrNCN}_{\mathrm{Eu}}{ }^{2+}-\mathrm{a}$ novel efficient orange-emitting phosphor, Chem. Mater. 23 (2011) 1694-1699.

[19] X. Tang, H. Xiang, X. Liu, M. Speldrich, R. A. Dronskowski, A ferromagnetic carbodiimide: $\mathrm{Cr}(\mathrm{NCN})_{3}$, Angew. Chem. Int. Ed. 49 (2010) 4738-4742.

[20] M. Krings, M. Wessel, W. Wilsmann, P. Muller, R. Dronskowski, Temperature-dependent synthetic routes to and thermochemical ranking of $\alpha-$ and $\beta$-SrNCN, Inorg. Chem. 49 (2010) 2267-2272.

[21] D. Koziej, F. Krumeich, R. Nesper, M. Niederberger, Nonaqueous liquid-phase synthesis of nanocrystalline metal carbodiimides. A proof of concept for copper and manganese carbodiimides, J. Mater. Chem. 19 (2009) $5122-5124$.

[22] X. Liu, M. A. Wankeu, H. Lueken, R. Dronskowski, A novel method for synthesizing crystalline copper carbodiimide, CuNCN. Structure determination by X-ray rietveld refinement, Z. Naturforsch. 60b (2005) 593-596.

[23] X. Liu, H. Puspitosari, R. Dronskowski, A novel method for synthesizing crystalline copper carbodiimide, $\mathrm{CuNCN}$ structure determination by X-ray rietveld refinement, Z. Anorg. Allg. Chem. 636 (2010) 121-125.

[24] M. G. Down, M. J. Haley, P. Hubberstey, R. J. Pulham, A. E. Thunder, synthesis of the dilithium salt of cyanamide in liquid lithium; X-ray crystal structure of $\mathrm{Li}_{2} \mathrm{NCN}, \mathrm{J}$. Chem. Soc. Chem. Commun. 2 (1978) 52-53.

[25] X. Liu, M. Krott, P. Muller, C. Hu, H. Lueken, R. Dronskowski, Synthesis, crystal structure, and properties of $\mathrm{MnNCN}$, the first carbodiimide of a magnetic transition metal, Inorg. Chem. 44 (2005) 3001-3003.

[26] A. A. Tsirlin, H. Rosner, Uniform spin-chain physics arising from N-C-N bridges in $\mathrm{CuNCN}$, the nitride analog of the copper oxides, Phys. Rev. B. 81 (2010) 1-10. 
[27] T.D. Boyko, R.J. Green, R. Dronskowski, A. Moewes, Electronic band gap reduction in manganese carbodiimide: MnNCN, J. Phys. Chem. C. 117 (2013) 12754-12761.

[28] X. Liu, P. Muller, P. Kroll, R. Dronskowski, Synthesis, structure determination, and quantum-chemical characterization of alternate $\mathrm{HgNCN}$ polymorph, Inorg. Chem. 41 (2002) 4259-4265.

[29] H. Xiang, X. Liu, R. Dronskowski, Theoretical reinvestigation of the electronic structure of $\mathrm{CuNCN}$ : the influence of packing on the magnetic properties, J. Phys. Chem. C. 113 (2009) 18891-18896.

[30] M. Becker, M. Jansen, Synthesis of potassium cyanamide, and crystal structure determination by pareto optimisation of the cost functions 'lattice energy' and 'powder intensities', Solid. State. Sci. 2 (2000) 711-715.

[31] A.A. Tsirlin, A. Maisuradze, J. Sichelschmidt, W. Schnelle, P. Hohn, R. Zinke, J. Richter, H. Rosner, Hidden magnetic order in CuNCN, Phys. Rev. B. 85 (2012) 1-16.

[32] X. Liu, R. Dronskowski, Characterization of the magnetic and structure properties of copper carbodiimide, $\mathrm{CuNCN}$, by neutron diffraction and first-principles evaluations of its spin exchange interactions, J. Phys. Chem. C. 112 (2008) 11013-11017.

[33] A. Thomas, A. Fischer, F. Goettmann, M. Antonietti, J.O. Muller, R. Schlogl, Graphitic carbon nitride materials: variation of structure and morphology and their use as metal-free catalysts, J. Mater. Chem. 18 (2008) 4893-4908.

[34] Q. Lv, C. Cao, C. Li, J. Zhang, H. Zhu, X. Kong, X. Duan, Formation of crystalline carbon nitride powder by a mild solvothermal method, J. Mater. Chem. 13 (2003) 1241-1243.

[35] D. Marton, K. J. Boyd, A.H. Al-Bayati, S.S. Todorov, J.W. Rabalais, Carbon nitride deposited using energetic species: A two-phase system, Phys. Rev. Lett. 73 (1994) 118-121. 
[36] V.N. Khabashesku, J.L. Zimmerman, J.L. Margrave, Powder synthesis and characterization of amorphous carbon nitride, Chem. Mater. 12 (2000) 3264-3270.

[37] E. Raymundo-Pinero, D. Cazorla-Amoros, A. Linares-Solano, J. Find, U. Wild, R. Schlogl, Structural characterization of n-containing activated carbon fibers prepared from a low softening point petroleum pitch and a melamine resin, Carbon. 40 (2002) 597-608.

[38] K. Morita, G. Mera, K. Yoshida, Y. Ikuhara, A. Klein, H. J. Kleebe, R. Riedel, Thermal stability, thermal stability, morphology and electronic band gap of Zn(NCN), Solid. State. Sci. 23 (2013) 50-57.

[39] F.P. Bowden, C.B.E., F.R.S., H.M. Montagu-Pollock, Slow decomposition of explosive crystals and their damage by fission fragments, Nature. 191 (1961) $556-559$ 


\section{Figure captions}

Fig. 1.Crystal structure of $\mathrm{CuNCN}$ with $\mathrm{Cu}$ in blue, $\mathrm{N}$ in red and $\mathrm{C}$ in grey.

Fig. 2. (a,c) FESEM images of small and large CuNCN MCs with the average diameters of $1.33 \pm 0.15 \mu \mathrm{m}$ and $4.12 \pm 0.64 \mu \mathrm{m}$ respectively. (b,d) The morphology of an individual small and large CuNCN MC respectively.

Fig. 3.Schematic illustration of two CuNCN MCs' formation process.

Fig. 4.(a) TEM image of a small CuNCN MC. (b) The morphology of the CuNCN MC's edge. (c) HRTEM image of the leaf-like nucleus in the CuNCN MC. (d) SAED of the leaf-like nucleus in the CuNCN MC.

Fig. 5. (a) XRD of the two CuNCN MCs. Curves a and b correspond to XRD of small and large CuNCN MCs respectively. (b) UV-vis absorbance spectroscopy of CuNCN MCs, the inset is plotting $(\alpha h v)^{2}$ (the square of the absorption coefficient $(\alpha)$ multiplied by the photon energy (hv)) versus hv. (c) Raman spectrum of CuNCN MCs. (d) FTIR of CuNCN MCs.

Fig. 6. (a) Overview XPS of the several elements in CuNCN MCs. (b,c,d) Cu 2p, C 1s and $\mathrm{N}$ 1s of the three elements in CuNCN MCs.

Fig. 7. Photoelectric responses of CuNCN MCs: J-V curves in the dark (black) and under visible light (red) illumination at room temperature. The inset is the measurement setup schematically.

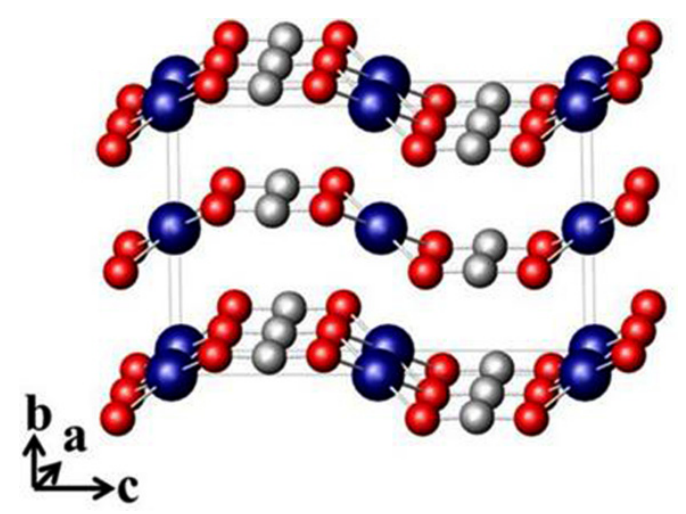

Fig.1 


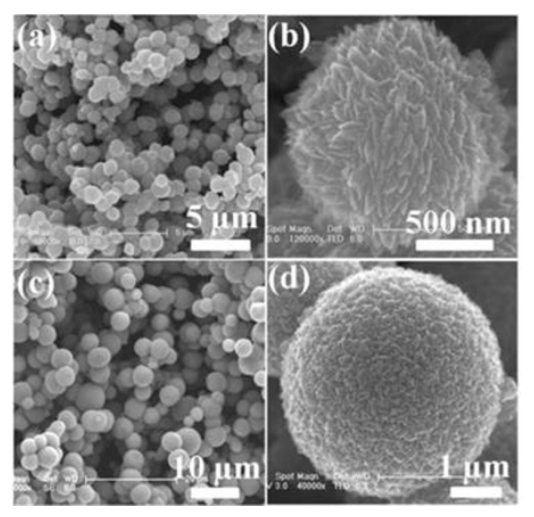

Fig. 2

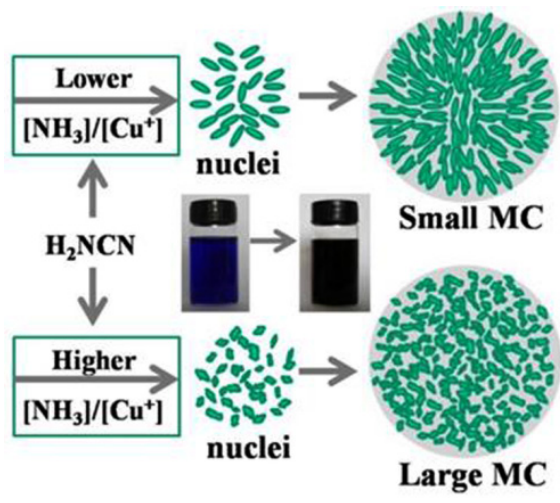

Fig. 3

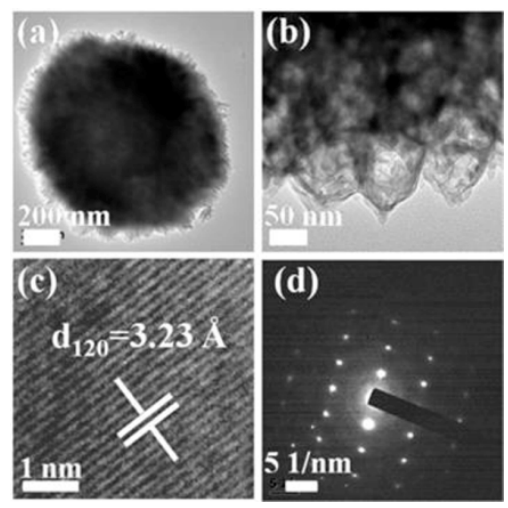

Fig.4 

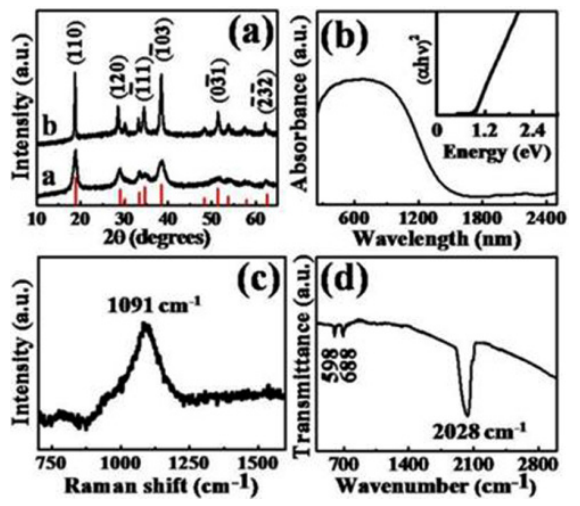

Fig. 5
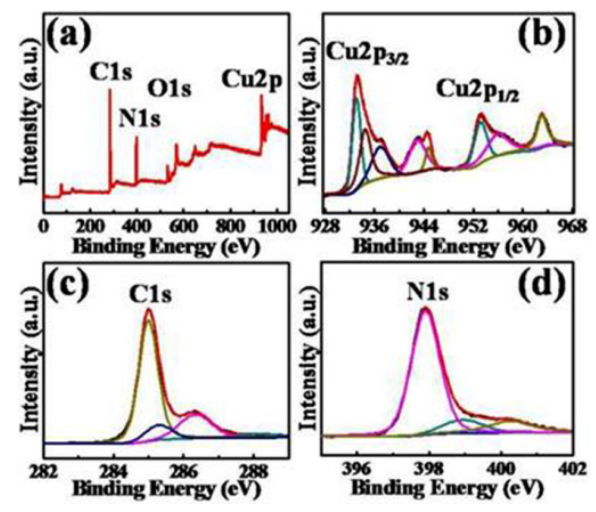

Fig.6

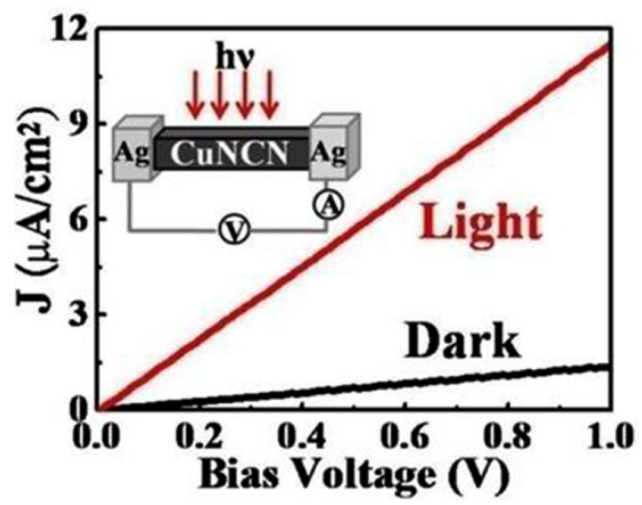

Fig. 7 


\section{Graphic Abstract}

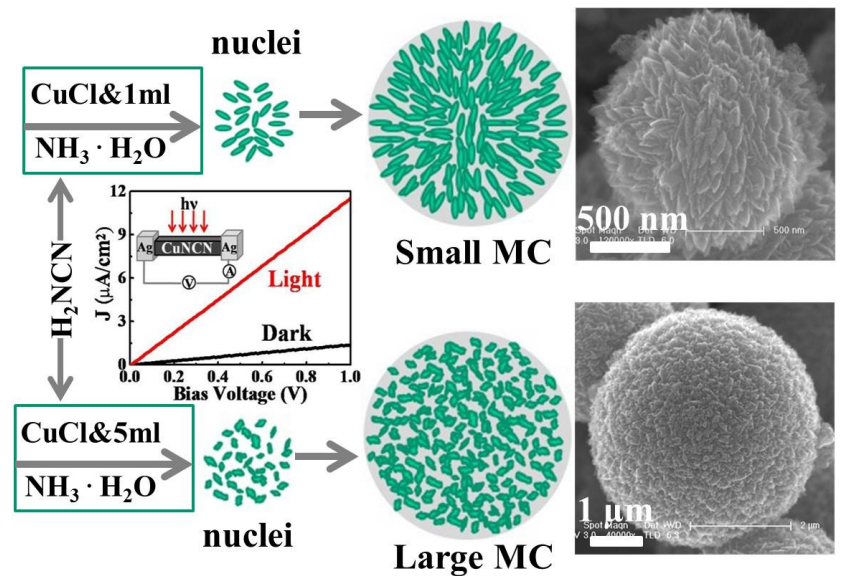

